\title{
Muscle cells challenged with saturated fatty acids mount an autonomous inflammatory response that activates macrophages
}

\author{
Nicolas J Pillon, Karen Arane, Philip J Bilan, Tim T Chiu and Amira Klip
}

\begin{abstract}
Obesity is associated with chronic low-grade inflammation. Within adipose tissue of mice fed a high fat diet, resident and infiltrating macrophages assume a pro-inflammatory phenotype characterized by the production of cytokines which in turn impact on the surrounding tissue. However, inflammation is not restricted to adipose tissue and high fat-feeding is responsible for a significant increase in pro-inflammatory cytokine expression in muscle. Although skeletal muscle is the major disposer of dietary glucose and a major determinant of glycemia, the origin and consequence of muscle inflammation in the development of insulin resistance are poorly understood.

We used a cell culture approach to investigate the vectorial crosstalk between muscle cells and macrophages upon exposure to physiological, low levels of saturated and unsaturated fatty acids. Inflammatory pathway activation and cytokine expression were analyzed in L6 muscle cells expressing myc-tagged GLUT4 (L6GLUT4myc) exposed to $0.2 \mathrm{mM}$ palmitate or palmitoleate. Conditioned media thereof, free of fatty acids, were then tested for their ability to activate RAW264.7 macrophages.

Palmitate -but not palmitoleate- induced IL-6, TNFa and CCL2 expression in muscle cells, through activation of the NF-KB pathway. Palmitate $(0.2 \mathrm{mM})$ alone did not induce insulin resistance in muscle cells, yet conditioned media from palmitate-challenged muscle cells selectively activated macrophages towards a pro-inflammatory phenotype. These results demonstrate that low concentrations of palmitate activate autonomous inflammation in muscle cells to release factors that turn macrophages pro-inflammatory. We hypothesize that saturated fat-induced, low-grade muscle cell inflammation may trigger resident skeletal muscle macrophage polarization, possibly contributing to insulin resistance in vivo.
\end{abstract}

Keywords: Inflammation, Muscle, Palmitate, Palmitoleate, Saturated fat, Obesity, Insulin resistance, GLUT4, Glucose uptake

\section{Lay abstract}

Obesity is associated with chronic activation of the immune system. In response to high fat diet, the fat tissue attracts immune cells that cause low, sustained inflammation responsible for making the body resistant to insulin. Recent studies show that inflammation also happens in muscle, but its origin and consequence for the development of type 2 diabetes are not understood.

We used cells in culture to investigate the communication between muscle and immune cells upon exposure to low levels of a saturated fatty acid (palmitate as in

\footnotetext{
* Correspondence: amira@sickkids.ca

Program in Cell Biology, The Hospital for Sick Children,Toronto, Ontario M5G $1 \times 8$, Canada
}

western diet) or an unsaturated fatty acid (palmitoleate, as in Mediterranean diet). We analyzed the effects of these fatty acids on muscle inflammation and next collected the solution surrounding these cells (called conditioned media), and tested its ability to activate immune cells.

Palmitate -but not palmitoleate- induced inflammation in muscle cells but the low dose used $(0.2 \mathrm{mM})$ alone did not make muscle cells resistant to insulin. Strikingly, conditioned media from palmitate-challenged muscle cells selectively made macrophages acquire a pro-inflammatory phenotype.

These results provide direct evidence of a muscle-toimmune cell communication in the context of fat exposure and suggest that this communication might occur 
in the body. This is of importance as fighting muscle inflammation could be a therapeutic strategy to prevent type 2 diabetes.

\section{Background}

One and a half billion people world-wide are overweight [1], and this condition is a leading cause of type 2 diabetes [2]. High caloric diet and in particular consumption of saturated fatty acids increase the likelihood of developing obesity. These conditions beget whole-body insulin resistance, a cornerstone of the metabolic syndrome, and obesity-induced insulin resistance is a major risk factor in the development of type 2 diabetes [3]. Palmitic acid (hexadecanoic acid, 16:0) is the most common saturated fatty acid in the western diet, and a major constituent of the total non-esterified fatty acids in the blood $[4,5]$. In cell and animal studies, palmitate leads to the development of insulin resistance and inflammation [6-8], whereas unsaturated fatty acids are often beneficial or at least less deleterious. Indeed, the monounsaturated fatty acid palmitoleic acid ((Z)-9-hexadecenoic acid, $16: 1 \Delta 9$ ), which differs from palmitate by the presence of one double-bond, increases insulin sensitivity and suppresses inflammation $[9,10]$.

Adipose tissue expansion in response to high fat diet (HFD) is accompanied by a local, low-grade inflammation [11-13]. In vivo, inflammation may be triggered by adipocytes and/or endothelial cells, putatively through the release of cytokines and other paracrine factors $[14,15]$. However, it is the resident macrophages and infiltrating macrophage-like cells that assume a proinflammatory phenotype, contributing to the brunt of pro-inflammatory cytokine production (e.g., TNF $\alpha$, IL-6 and IL-1 $\beta$ ) within adipose tissue $[16,17]$. Whereas the initial trigger of inflammation in the adipose tissue is debated, high levels of palmitate and other saturated fats promote a pro-inflammatory phenotype in macrophages in vitro $[18,19]$. In turn, inflamed immune cell populations can adversely affect the metabolic function of adipose tissue; and indeed, inflammation per se can impair insulin action in adipocytes, reducing lipogenesis and enhancing lipolysis [15,20].

In spite of the pivotal role of macrophages in the development of insulin resistance within adipose tissue during HFD, inflammation is not restricted to this tissue. Indeed, HFD is responsible for a significant increase in the expression of the pro-inflammatory cytokines TNF $\alpha$, IL-6 and IL-1 $\beta$ in skeletal muscle [21]. This is important because skeletal muscle is the major disposer of dietary insulin and a major determinant of glycemia, and wholebody insulin resistance arises only when skeletal muscle and/or the liver become resistant to the actions of insulin [22]. In addition, resident macrophages are a constitutive component of skeletal muscle, relevant for inflammatory responses associated with muscle injury, dystrophies and endotoxemia [23,24]. Notably, we and others recently detected increased gene expression of F4/80 (macrophage marker) and CD11c ${ }^{+}$(pro-inflammatory macrophage- or dendritic cell-like) in muscle from high fat-fed mice $[12,25]$. Moreover, upon extraction and flow cytometry, we detected a population of F4/80/CD $11^{+}$ cells (inflammatory macrophages), and others have observed macrophages in fat depots within muscle that expand under HFD and obesity $[13,26]$. Notably, macrophages increase in number within skeletal muscle from obese subjects and their number and inflammatory phenotype correlate positively with body mass index and negatively with insulin sensitivity [25,27]. Compellingly, media collected from saturated fatty acid-treated macrophages confer insulin resistance to muscle cells in culture $[12,14,18]$.

While those studies provide pieces of evidence of communication from macrophages to muscle cells, they did not examine the communication from muscle cells to macrophages, and the reason for macrophages turning inflammatory in the muscle (or adipose) tissue milieu is unknown. Conceivably, muscle cells on their own generate cues that can impact on macrophages. The major aim of this study was to test the hypothesis that low levels of saturated fatty acids evoke inflammatory responses in muscle cells that may in turn affect the macrophage phenotype. A cell culture model was used to provide proof-of-principle of muscle to macrophage communication, as it avoids the complexities expected from a whole-body analysis. The results demonstrate that, at low doses, palmitate activates inflammatory pathways within muscle cells leading to the expression of inflammatory cytokines, and media collected from these cells shifts macrophages towards a pro-inflammatory mode. Conversely, the unsaturated palmitoleate did not activate inflammatory pathways in muscle cells, and media thereof did not confer a pro-inflammatory phenotype to macrophages. These results provide direct evidence of a muscle to macrophage communication in the context of exposure to saturated fat.

\section{Results}

Skeletal muscle is composed primarily of muscle fibers, but also encompasses blood and lymph vessels, nerves and immune cells. As each of these cell types can potentially respond to a high fat environment in vivo, we chose a cell culture approach to investigate the specific crosstalk between muscle cells and macrophages in the context of fatty acid exposure. This strategy enables us to control individual variables, to determine vectorial communication, and to explore separately the responses of each cell type. L6GLUT4myc cells were used as a prototypic muscle cell system that responds to insulin 
[28] while RAW264.7 macrophages were used as they constitute a well-characterized macrophage line [12]. Palmitate was used as a typical saturated fatty acid found in western diets and palmitoleate was used to decipher the contribution of acyl chain saturation in palmitate. From healthy to obese individuals, total free fatty acid concentration in serum can range from 0.2 to $0.8 \mathrm{mmol} / \mathrm{L}$, composed of roughly $25 \%$ palmitate and $4 \%$ palmitoleate $[5,29,30]$. Consequently, palmitate can reach up to 0.2 $\mathrm{mM}$ in obese individuals [4], which is the concentration we chose to use in our study. Each fatty acid was conjugated to low endotoxin and lipid-free BSA, and control treatment with BSA was carried out in parallel. BSA and fatty acid-BSA were removed from the muscle cultures prior to further incubation to generate the respective conditioned media, and non-esterified free fatty acids were undetectable in such conditioned media (Table 1). These fatty acid-free conditioned media are hereafter called CM-PA (collected from muscle cells pretreated with PA); CM-PO (from muscle cells pretreated with PO), or CM-BSA (from muscle cells pretreated only with BSA).

\section{Low-dose palmitate up-regulates cytokine gene expression in muscle cells}

Gene expression by muscle cells of a number of cytokines was measured by qPCR. IL- 6 was the most abundantly expressed cytokine in muscle cells, relative to a housekeeping control gene, whereas TNF $\alpha$ expression was barely detectable and IL-1 $\beta$ was undetectable (data not shown). Treatment with palmitate -but not palmitoleate- increased IL-6 and TNF $\alpha$ gene expression by 3.8- and 4-fold, respectively, compared to the BSA control (Figure 1A) These results suggest that TNF $\alpha$ and IL-6 are bona fide muscle cell products up-regulated in response to a palmitate challenge. Accordingly, we used IL- 6 as the prototypical cytokine produced by muscle under a palmitate challenge. IL-6 expression was induced by palmitate in a time-dependent manner measured for up to $24 \mathrm{~h}$ (Figure 1B).

In an attempt to characterize the molecules released by muscle cells present in the conditioned media (CM), we used a protein array that was able to detect several

Table 1 NEFA concentration

\begin{tabular}{lll}
\hline & Initial & CM \\
\hline RM & $25 \pm 25$ & $<10$ \\
BSA & $15 \pm 14$ & $<10$ \\
PA & $197 \pm 58$ & $<10$ \\
PO & $252 \pm 80$ & $<10$ \\
\hline
\end{tabular}

NEFA concentration in the initial solution and conditioned media (CM) was measured using the enzymatic method based on Acyl-CoA oxidase as described in methods. The measurable range of the kit is $0.01-4.0 \mathrm{mM}$. Results are means \pm SD expressed in micromoles/liter from at least 4 independent experiments $(n \geq 4)$.
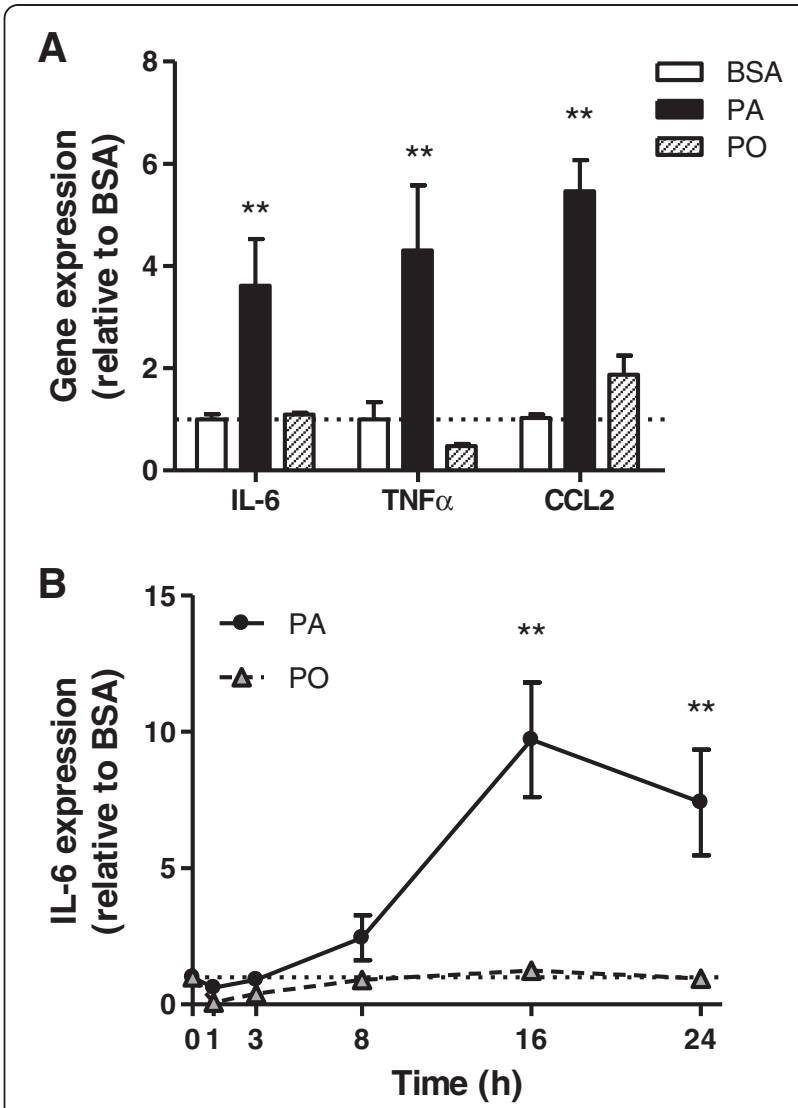

Figure 1 Low level palmitate treatment activates inflammatory cytokine \& chemokine gene expression in muscle cells. L6 muscle cells were treated with $0.2 \mathrm{mM}$ palmitate $(\mathrm{PA})$, palmitoleate $(\mathrm{PO})$ or $\mathrm{BSA}$ control for (A) $24 \mathrm{~h}$ or (B) at the times indicated. A) mRNA expression was analyzed by qRT-PCR using primers for TNFa IL-6 and CCL2. B) mRNA expression was analyzed by qRT-PCR using primers for IL-6. Results are normalized to the reference gene hprt1 and then to the BSA control and reported as fold change \pm SEM $(n \geq 3),{ }^{* *} p<0.01$ vs BSA control (1-way ANOVA).

cytokines and chemokines (Additional file 1: Figure S1). Attention was paid to expose the CM-BSA and CM-PA arrays for precisely the same time. Notably, PDGF levels were decreased in the CM-PA array, while there was an overall elevation in several other cytokines, demonstrating that differences observed between the two samples are not generic. The most abundant cytokines and factors within either $\mathrm{CM}$ revealed by this approach were CINC1 (CXCL1), PDGF, VEGF and TIMP1. TIMP1 is an inhibitor of matrix metalloproteinases, which is also involved cell proliferation and apoptosis. VEGF and PDGF are growth factors involved in vasculogenesis and angiogenesis and CINC1 (CXCL1) promotes neutrophil migration. None of these factors have been shown to induce inflammation in macrophages.

Although small, there were discernible elevations in IL-6 and CCL2 levels in the CM-PA compared to CM$\mathrm{PO}$ array, consistent with the detectable rises in their 
mRNA levels in the corresponding cells (Figure 1 and Additional file 1: Figure S1). On the other hand, there was no detectable TNF $\alpha$ protein (Additional file 1: Figure S1), and this is also consistent with the very low mRNA expression detected in the cell lysates. Other proteins that were clearly higher in CM-PA compared to CM-PO included activin A, agrin, INF $\gamma, \mathrm{IL}-1 \alpha$ and MIP $3 \alpha$.

\section{Signalling pathways activated by low-dose palmitate}

Obesity and type 2 diabetes are associated with activation of stress kinases, as well as activation of the canonical NF- $\mathrm{kB}$ inflammation pathway in several tissues [31]. I $\kappa \mathrm{B} \alpha$ degradation is necessary for NF- $\kappa \mathrm{B}$ migration to the nucleus to initiate cytokine transcription. Mitogen Activated Protein Kinases (MAPK) and Reactive Oxygen Species (ROS) are known activators of this pathway [32]. In L6 muscle cells, palmitate treatment significantly increased ROS levels by $25 \%$ (Figure 2A), and caused phosphorylation of Extracellular Regulated Kinase 1/2 (ERK1/2) and p38 MAPK, whereas JNK was not phosphorylated (Figure 2B-D and Figure 2F). In contrast to palmitate, palmitoleate did not significantly activate any of these stress kinases or ROS production, although JNK phosphorylation tended to be higher. Palmitate also caused significant activation of the NF- $\mathrm{kB}$ pathway, revealed by a $50 \%$ reduction in $\mathrm{I} \kappa \mathrm{B} \alpha$ mass (Figure $2 \mathrm{E}-\mathrm{F}$ ) that was time-dependent, reaching its lowest point by $24 \mathrm{~h}$ of treatment (Figure 2G).

To explore the involvement of the NF- $\mathrm{B}$ pathway in palmitate-induced cytokine expression, we silenced the expression of the p65 subunit of the NF- $\mathrm{kB}$ complex via siRNA oligonucleotides. In cells depleted of p 65 protein by $70 \%$, palmitate-induced expression of IL-6 was abolished, whereas a control non-related siRNA failed to diminish the palmitate effect (Figure 3A). Silencing p65 also prevented the palmitate-induced rise in TNF $\alpha$ and CCL2 expression (Additional file 1: Figure S2). On the other hand, although palmitate stimulated ROS production in muscle cells, the rise in cytokine expression caused by palmitate was not prevented by the antioxidant $\mathrm{N}$-acetyl-cysteine despite its clear ability to lower ROS levels (Figure 3B). Hence, ROS are unlikely to be a signal
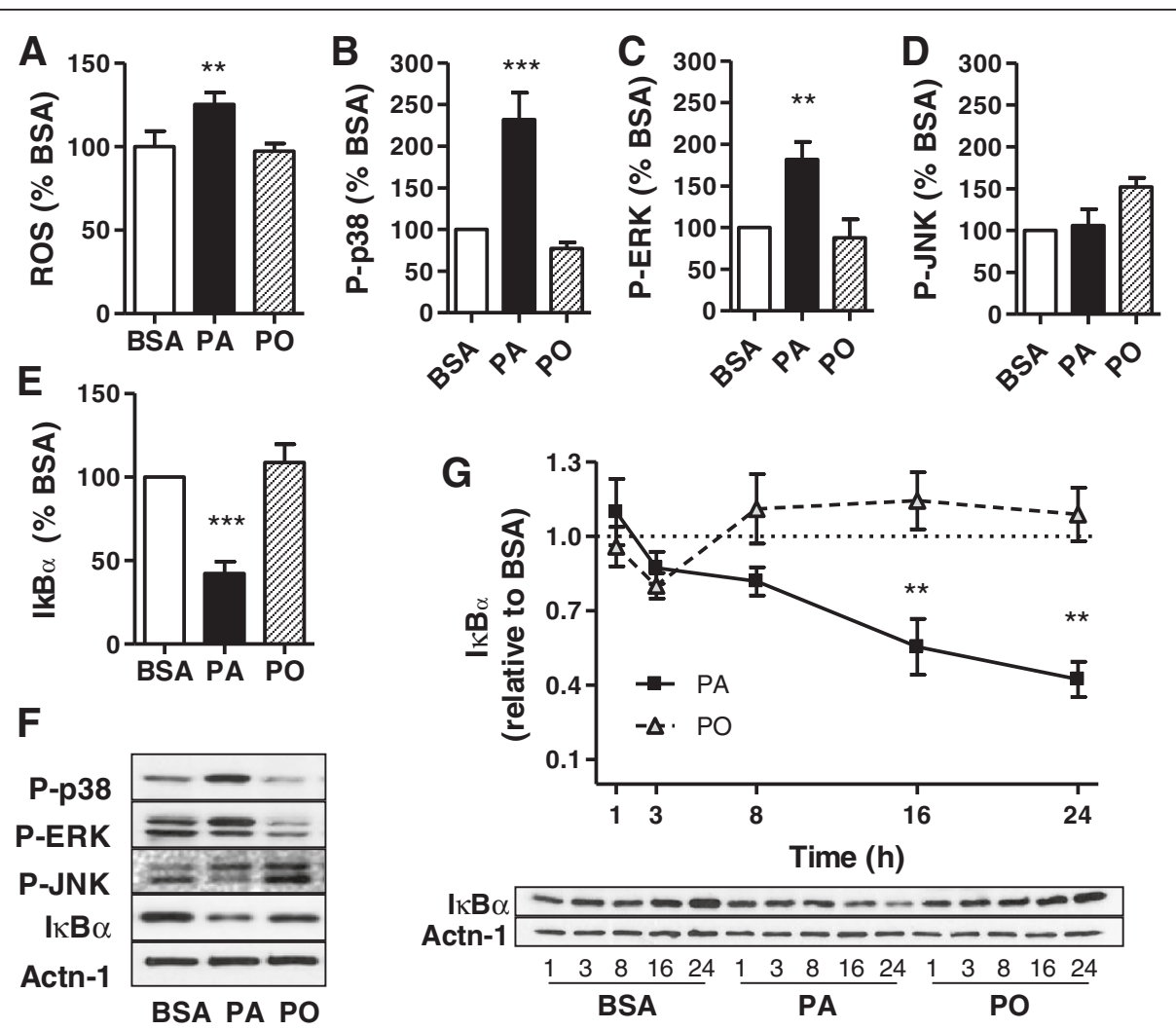

Figure 2 Palmitate activates ROS and signalling pathways in muscle cells. $L 6$ muscle cells were treated for $24 \mathrm{~h}$ with $0.2 \mathrm{mM}$ palmitate (PA), palmitoleate (PO) or BSA control. A) Reactive oxygen species were analyzed using DCFDA, normalized to the protein content and expressed as percent of the BSA control. Results are mean \pm SEM $(n=4)$ analyzed using 1-way ANOVA, ${ }^{* *} p<0.01$ vs BSA control. B-E) Proteins were extracted with standard lysis buffer and analyzed by western blotting using specific antibodies to IKBa and the phosphorylated forms of ERK, JNK and p38 MAPK. Results were normalized to the loading control actinin-1, expressed relative to the BSA control as mean \pm SEM $(n=4)$ and analyzed using 1-way ANOVA, ${ }^{* *} p<0.01,{ }^{* * *} p<0.001$ vs BSA control. F) Representative blots for B-E. G) Time-course of IkBa degradation. The changes of I KBa were calculated to the BSA control as indicated by the dotted line set at 1.0 from the $y$-axis ${ }^{* *} p<0.01$ vs BSA control. 


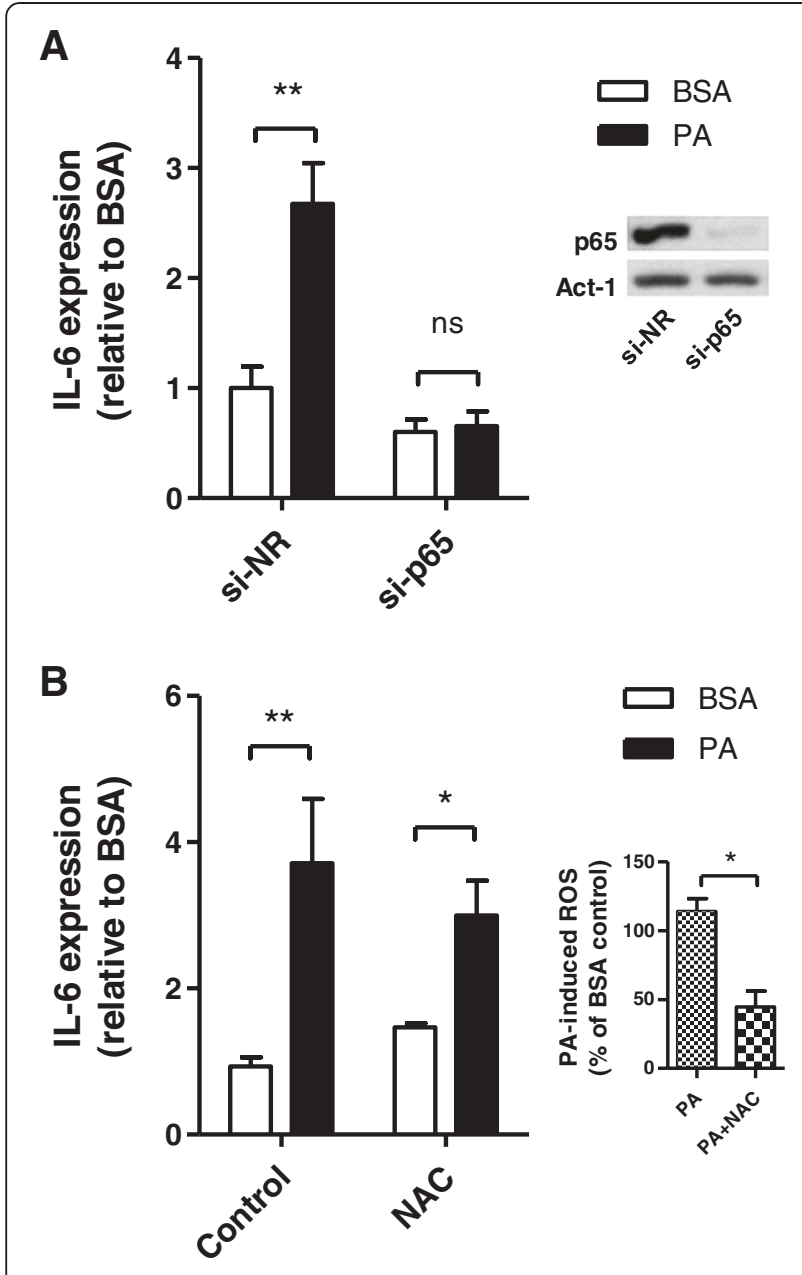

Figure 3 Palmitate-induced cytokine expression occurs through NF-KB pathway. A) NF-KB was silenced using specific siRNA to the p65 subunit (p65) or control non-related siRNA (NR) before treatment of cells for $24 \mathrm{~h}$ with $0.2 \mathrm{mM}$ palmitate or BSA. B) Cells were incubated in the presence of $0.2 \mathrm{mM}$ palmitate or BSA without or with $\mathrm{N}$-acetyl-cysteine ( $5 \mathrm{mM}$ ) for $24 \mathrm{~h}$. Inset: ROS production was measured as described in Figure $2 \mathrm{~A}$ and reported as percent of the BSA control. All results were normalized to BSA control and reported as fold change \pm SD from at least 3 independent experiments $(n \geq 3)$. ${ }^{*} p<0.05,{ }^{* *} p<0.01, n s=$ non significant.

for the cytokine expression by muscle cells evoked by the fatty acid.

\section{Low-dose palmitate does not confer insulin resistance to muscle cells}

The above results show that physiological levels of palmitate $(0.2 \mathrm{mM})$ activated stress and inflammatory pathways in muscle cells. Because much elevated levels of palmitate $(0.5 \mathrm{mM}$ and higher $)$ can induce insulin resistance in muscle cells, in part through the generation of oxidative stress $[6,33,34]$, we explored if this would similarly occur in response to low palmitate. Interestingly, though $24 \mathrm{~h}$ incubation of muscle cells with $0.2 \mathrm{mM}$ palmitate activated NF- $\mathrm{kB}$ signalling and IL- 6 expression (shown above, Figures 1, 2, and 3), this did not diminish the classical insulin responses of GLUT4 translocation (Figure 4A) and in fact, increased glucose uptake (Figure 4B). At this low palmitate exposure, insulin stimulated GLUT4 translocation by 2.3-fold and glucose uptake by $60 \%$, comparable to the response of BSA-treated control cells. Hence, the milder lipid exposure can activate inflammation, but is not sufficient on its own to cause insulin resistance in isolated muscle cells.

As conditioned media from palmitate-treated muscle cells (CM-PA) contain several cytokines and chemokines that might provoke insulin-resistance in muscle cells as shown in other studies [35-37], we also assessed whether such CM would exert an autocrine insulin resistance effect, independently of any direct metabolic effect of palmitate. To this end, CM-PA or CM-BSA were applied to sets of naive L6 cells for $24 \mathrm{~h}$. Following incubation, insulin stimulated GLUT4 translocation by $70 \%$ in both conditions (Figure $4 \mathrm{C}$ ) and glucose uptake by $80 \%$ and $60 \%$, respectively (Figure 4D). There was no statistical difference between the responses to CM-BSA and CMPA, indicating the absence of muscle-to-muscle autocrine transmission of insulin-resistance.

\section{Conditioned medium from muscle cells promotes macrophage inflammation}

Given the increased gene expression of cytokines and chemokines in palmitate-treated muscle cells and the elevated levels in CM-PA, we explored whether this medium could affect macrophage function and phenotype. Activated macrophages are characterized by stimulation of the MAPK signalling pathways [38], as well as actin filament remodelling extending filopodia and lamellipodia that promote cell spreading [39]. RAW macrophages responded to CM-PA with a rise in phosphorylation of ERK, p38 MAPK and JNK (Figure 5A). In contrast, CM-PO only provoked ERK phosphorylation. Macrophages treated with either CM-PA or CM-PO assumed an elongated shape visualized upon actin filament decoration with rhodamine-phalloidin (Figure 5B-D), and showed heightened adherence to the substratum, compared to CM-BSA-treated controls (Figure 5E).

Inflammatory macrophages are typified by elevated gene expression of the pro-inflammatory cytokine TNF $\alpha$ and the enzyme iNOS, with converse diminished gene expression of the anti-inflammatory cytokine IL-10 [40]. Macrophages exposed to CM-PA exhibited an increased expression of TNF $\alpha$ and iNOS mRNA but no significant change in IL-10 and CCL2 mRNA (Figure 6). On the other hand, CM-PO did not affect the expression of any of these genes.

Since the analysis of the CM (Additional file 1: Figure S1) revealed that many changes were modest, this suggested 

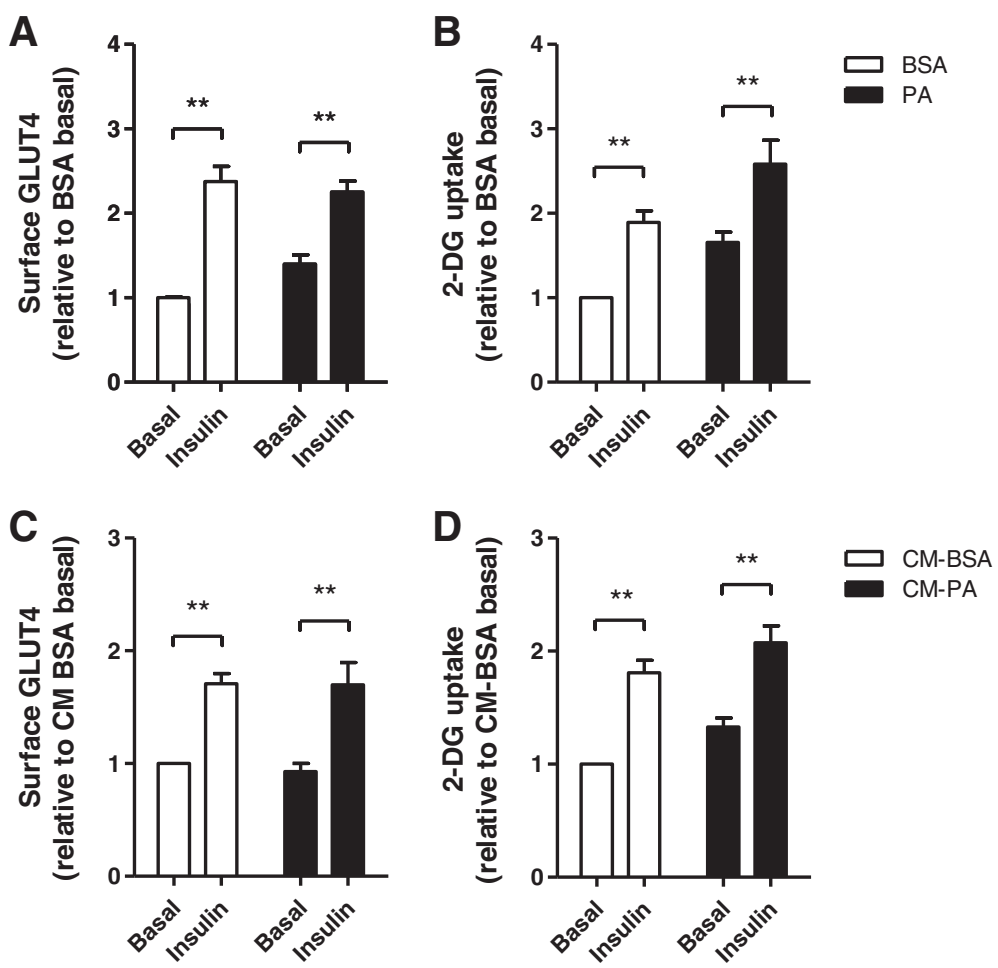

Figure 4 Palmitate treatment does not induce insulin-resistance in muscle cells. A-B) The direct effect of PA was measured by treating L6 cells with $0.2 \mathrm{mM}$ palmitate (PA), palmitoleate (PO) or BSA control for $24 \mathrm{~h}$, followed by $3 \mathrm{~h}$ serum starvation and insulin stimulation (20 min, $100 \mathrm{nM}$ ) in the absence of PA. C-D) The indirect effect of palmitate through a possible autocrine effect was tested by generating conditioned media from muscle and applying it on naive untreated muscle cells. Surface GLUT4myc and glucose uptake were measured as described in Methods. Results are normalized to the CM-BSA control and expressed as mean \pm SEM $(n=4),{ }^{* *} p<0.01$.

that the active component is either not detected by this array, that molecules other than cyto/chemokines contribute, and/or that a complex mechanism involving synergistic effects of low levels of several cytokines and chemokines may participate in conferring macrophage polarization. Therefore, as preamble, we ascertained whether proteins mediate this cell-cell communication. $\mathrm{CM}$ were boiled $\left(95^{\circ} \mathrm{C}, 15\right.$ minutes) or treated with proteinase $\mathrm{K}(100 \mu \mathrm{g} / \mathrm{mL}, 2 \mathrm{~h})$ to digest proteins, and the enzyme itself was then heat inactivated. Both of these strategies successfully blunted induction of TNF $\alpha$ mRNA expression within macrophages provoked by muscle CM-PA (Additional file 1: Figure S3). This demonstrates that the factor(s) responsible for macrophage polarization of macrophages is (are) of protein nature. These results highlight a protein-mediated, muscleto-macrophage communication that confers an inflammatory phenotype to the latter, when the former are pre-exposed to a saturated fatty acid.

\section{Discussion}

Recent studies have detected elevated numbers of myeloid cell or macrophage markers in skeletal muscle during HFD and obesity [13,25-27], but how these immune cells are influenced by the surrounding tissue and their role in the progression of insulin resistance are unknown. Here we present evidence that muscle cells exposed to a physiological dose of the saturated fatty acid palmitate, activate their endogenous inflammatory programs and that conditioned-medium from such challenged muscle cells induces a pro-inflammatory phenotype in macrophages. In contrast to palmitate, the monounsaturated fatty acid palmitoleate had no significant effect on muscle cell autonomous inflammation or on the crosstalk from muscle cells to macrophages. Overall, these results lend support to the hypothesis that in vivo, skeletal muscle may contribute to the low-grade inflammation observed during high fat diet through the production of cytokines affecting immune cell responses. The latter could be either resident or recruited macrophages, and their bi-directional crosstalk with muscle cells might contribute to muscle insulin resistance during dyslipidemia or HFD earlier than the development of direct, lipid-induced insulin resistance.

\section{Low-dose palmitate elicits muscle cell-autonomous inflammation}

Myoblasts treated with palmitate exhibit activation of pathways leading to inflammation, specifically activating 

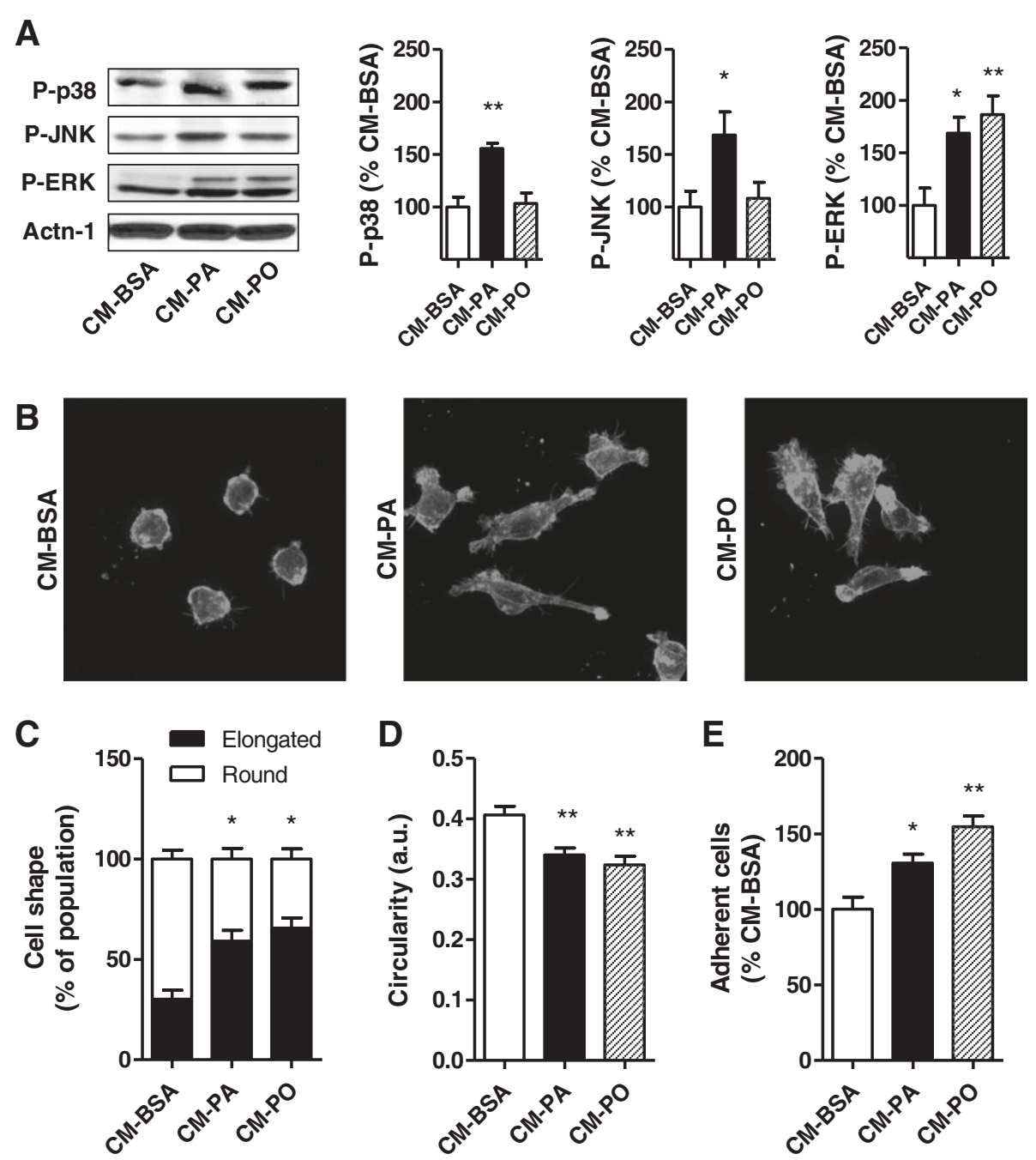

Figure 5 Muscle cell conditioned media induce macrophage spreading and adhesion. Conditioned media (CM) from myoblasts treated with $0.2 \mathrm{mM}$ palmitate was applied on RAW264.7 macrophages for $2 \mathrm{~h}$. A) Proteins were extracted and analyzed by western blotting using specific phospho antibodies to ERK, JNK and p38 as previously described. B-C) Actin labelling with rhodamine phalloidin and cell shape quantification were performed as described in Methods. E) Circularity in images was quantified with ImageJ software. E) Measurement of RAW264.7 cell adhesion in response to CM, as described in Methods. Results were normalized to BSA control, reported as fold change \pm SD and analyzed using 1-way ANOVA, $n \geq 3,{ }^{*} p<0.05,{ }^{*} p<0.01$.

MAPK, elevating ROS and inducing IкB $\alpha$ degradation (Figure 2). A similar response is observed in response to higher palmitate concentrations [41,42]. Low levels of palmitate also led to increased gene expression of several pro-inflammatory cytokines (TNF $\alpha$, IL-6) and chemokines (CCL2), as well as greater release of several cytokines from muscle such as INF $\gamma$, IL- $1 \alpha$, IL-6, CCL2, TIMP1 and CXCL1, demonstrating the development of muscle cell-autonomous inflammation. This process was evident by $8 \mathrm{~h}$ of incubation with palmitate, and peaked by $16 \mathrm{~h}$, evincing the activation not only of posttranslational signalling, but also of transcriptional and metabolic events (i.e., ROS production). Interestingly, palmitoleate did not activate any of these pathways in the muscle cells, and did not change cytokine expression. The palmitate-induced increase in cytokine gene expression is not as impressive as that typically elicited by LPS, rather it is slow, sustained, and the fold-change is comparable to that reported in muscle from obese vs. lean mice [21].

TLR4 and TLR2 have been invoked to participate in some response to saturated fatty acids in cell culture and to HFD in vivo [43-45]. Indeed, TLR4 deficient mice exhibit decreased NF- $\mathrm{kB}$ activation in adipose tissue in response to a diet rich in palmitate [46], and inhibition or deletion of TLR4 confers partial protection against palmitate-induced NF- $\mathrm{KB}$ activation in rodent skeletal muscle [47]. However, other pattern recognition receptors 


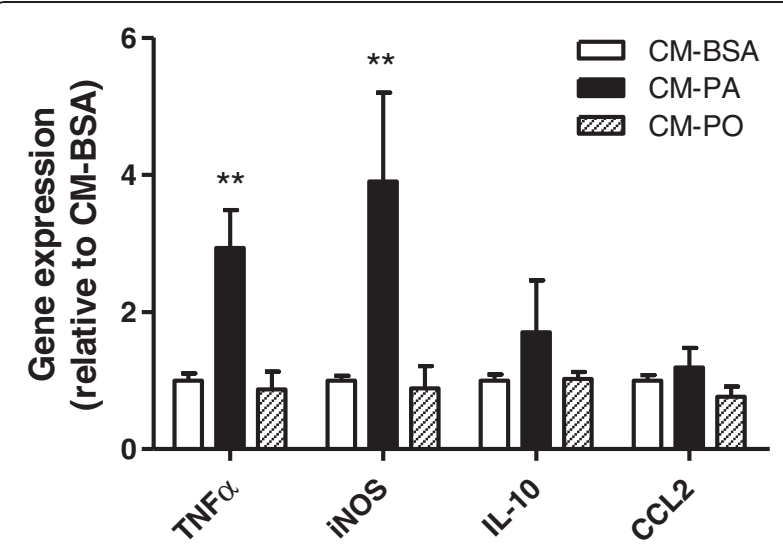

Figure 6 Muscle cell conditioned media induce macrophage inflammation. Conditioned media (CM) from myoblasts treated with $0.2 \mathrm{mM}$ palmitate was applied on RAW264.7 macrophages for $6 \mathrm{~h}$ and gene expression in RNA of the latter was measured by $\mathrm{qPCR}$ as described in Methods. Results were normalized to the BSA control, reported as fold change \pm SD and analyzed using 1-way ANOVA, $n \geq 3,{ }^{* *} p<0.01$.

such as Nod1 and Nod2 also funnel their signals through NF-kB. Muscle cells express these receptors, and we have found that agonist-induced activation of Nod2 causes IкB $\alpha$ degradation and TNF $\alpha$ expression in these cells [48]. Future work should explore whether TLRs, Nod1 or Nod2 participate in the inflammatory response of muscle cells induced by palmitate. The current study also shows that $0.2 \mathrm{mM}$ palmitate increased muscle cell ROS levels (Figure 2A), as it occurs in response to higher palmitate concentrations [49]. Dampening such ROS levels with $\mathrm{N}$-acetyl-cysteine failed to attenuate the palmitateinduced cytokine production, but we cannot rule out that the remaining ROS levels might be permissive for cytokine production under these conditions.

\section{Muscle cell-autonomous inflammation via NF-KB does not suffice to cause insulin resistance}

The NF- $\kappa B$ pathway, which controls the expression of inflammatory cytokines, is involved in the pathogenesis of whole-body insulin resistance [50,51]. NF- $\mathrm{kB}$ activity is 2.7 -fold higher in muscles from obese type 2 diabetic subjects compared to lean individuals [52] and this difference is conserved in human primary myocytes in culture derived from obese type 2 diabetic patients [50]. However, the cause for the activation is likely complex and may result from the combined input of signals derived from other cells on the muscle, along with the elevated cytokines and fatty acids in the circulation. Further, in muscle cell cultures, very high concentrations of palmitate (0.5-0.8 $\mathrm{mM}$ ) activate novel-type protein kinase C's in addition to the NF- $\kappa B$ pathway $[41,42]$ and elevate the expression of IL-6, compromising insulin signalling and further causing GLUT4 down-regulation
$[41,53]$. Here we present evidence that preventing muscle cell-autonomous activation of the NF- $\mathrm{kB}$ pathway via knockdown of the p65 NF- $\mathrm{BB}$ subunit eliminates the palmitate-induced upregulation of IL-6, TNF $\alpha$ and CCL2 expression.

Importantly, in spite of causing muscle cell-autonomous inflammation involving NF- $\mathrm{kB}$ signalling and cytokine production, low levels of palmitate did not provoke insulin resistance of GLUT4 translocation or glucose uptake. Hence, engagement of the NF- $\mathrm{kB}$ pathway per se is insufficient to alter the major insulin action in skeletal muscle cells. It is possible that this pathway would be relevant if other stress signals were activated, and notably palmitate did not cause JNK phosphorylation in muscle cells. Activation of this kinase is a typical feature of insulin resistant muscle in the context of HFD in vivo, and a recent study shows that muscle-specific transgenic expression of constitutively-active JNK per se confers insulin resistance [54]. Further, our results indicate that any cytokines present in $\mathrm{CM}$ from palmitate-treated muscle cells do not suffice to confer insulin resistance to naive muscle cells (i.e., muscle-to-muscle communication) while the same CM was able to activate macrophages (discussed below).

\section{Muscle cells confer macrophage pro-inflammatory polarization}

A core result of this study is that muscle cells pre-treated with low-dose palmitate produce $\mathrm{CM}$ that makes macrophages assume a pro-inflammatory phenotype. Specifically, CM-PA induced activation in macrophages of selective MAPK signalling pathways (p38 and JNK), along with promoting cell spreading and gene expression of the pro-inflammatory markers TNF $\alpha$ and iNOS. These results render proof-of-concept that muscle cells can release factors communicating with immune cells in the context of physiological levels of saturated fat. On the other hand, CM from palmitoleate-treated muscle cells did not bring about these responses, suggesting that unsaturated fatty acids do not elicit muscle-to-macrophage crosstalk. Boiling and proteinase $\mathrm{K}$ treatments of CM-PA blunted the power of this medium to confer inflammation to macrophages, suggesting that the factor(s) released by muscle is (are) cytokine(s) or other proteins. Cytokine array analysis did not reveal any salient increases in cytokines in CM-PA compared to CM-PO, however the array is limited and it is also possible that levels below the detection limit of the array, or proteins not analyzed, confer polarization. A synergistic effect of low-doses of several different factors is also possible, and indeed in 3T3-L1 adipocytes, LPS, tumor necrosis factoralpha (TNF $\alpha$ ), or interferon-gamma (IFN $\gamma$ ) had to be combined to increase iNOS activity [55]. Further indepth analysis, beyond the scope of the present study, 
will be necessary to identify the proteins and/or synergistic effects involved in the muscle-macrophage crosstalk described.

Of note, CM-PO resembled CM-PA in its ability to activate ERK in macrophages, and this response is consistent with the morphological change of macrophages induced by both media, characterized by cell spreading. ERK is involved in lamellipodia protrusion [56], and consistent with these observations, inhibiting ERK prevented the heightened macrophage adhesion elicited by either CM-PA or CM-PO (Additional file 1: Figure S4). Interestingly, cell spreading is a feature of both pro- and anti-inflammatory macrophages [57]. We therefore surmise that macrophage adhesion and pro-inflammatory activation in response to muscle cell CM are not obligatorily linked, as the two responses can be dissociated depending on the pretreatment of the muscle cells. These results illustrate that different nutrients promote a distinct muscle-to-macrophage crosstalk. Immune cells can be activated in muscle for beneficial outcomes such as resolving injury [58], and we hypothesize that CM-PO might counteract inflammatory cues acting on macrophages; future studies should explore this possibility.

In conclusion, we report that physiological levels of palmitate cause muscle cell-autonomous inflammation that, while not sufficing to cause insulin resistance within the muscle cells, result in production of proteins conferring a pro-inflammatory phenotype to macrophages in culture. If one may extrapolate, it is conceivable that muscle-induced macrophage polarization is one of the most sensitive responses to a saturated fat environment in vivo. Given the ability of pro-inflammatory macrophages to confer insulin resistance to muscle, we hypothesize that a feed-forward cycle of muscle-macrophage cross talk can contribute to the development and perpetuation of full-blown insulin resistance.

\section{Methods \\ Reagents}

Sodium palmitate, palmitoleate, BSA (low endotoxin), endotoxin-free water and protease inhibitor cocktail were from Sigma-Aldrich. Antibodies to phospho-JNK (Thr183/Tyr185), phospho-ERK (Thr202/Tyr204), phosphop38 MAPK (Thr180/Tyr182), and IкB $\alpha$ were from Cell Signaling Technology (Beverly, MA). Control siRNA (siNR) and siRNA against p65 were purchased from Qiagen (Chatsworth, CA) and MYD88 inhibitory and control peptides were from Invivogen (San Diego, CA). 2-Deoxy- $\left[{ }^{3} \mathrm{H}\right]$ glucose was from Perkin Elmer.

\section{Fatty acid preparations}

Solutions of $200 \mathrm{mM}$ sodium palmitate or palmitoleate were prepared in $50 \%$ ethanol by heating at $55^{\circ} \mathrm{C}$ and vortexing until dissolved. These solutions were diluted
25 -times in a $10 \%$ fatty acid-free, low-endotoxin BSA solution to achieve a final molar ratio of 5:1. Conjugation was done at $40^{\circ} \mathrm{C}$ for $2 \mathrm{~h}$. BSA-fatty acid conjugates were further diluted 40 -fold in cell culture media to reach a final concentration of $0.2 \mathrm{mM}$ palmitate or palmitoleate. Control BSA was prepared by adding the same amount of $50 \%$ ethanol into a $10 \% \mathrm{BSA}$ solution. All preparations were aliquoted and frozen at $-20^{\circ} \mathrm{C}$.

\section{Cell culture and transfection}

Rat L6 muscle cells with stable expression of myc-tagged glucose transporter 4 (L6GLUT4myc), and RAW264.7 macrophages were each grown in $\alpha$-MEM supplemented with $10 \%$ fetal bovine serum (FBS), 100 units $/ \mathrm{mL}$ penicillin, $100 \mu \mathrm{g} / \mathrm{mL}$ streptomycin and $250 \mathrm{ng} / \mathrm{mL}$ amphotericin B. siRNAs oligonucleotides were transfected into the cells with calcium phosphate-based CellPhect Transfection Kit (GE Healthcare Bio-Sciences, Piscataway, NJ). Muscle cells were treated with $200 \mathrm{nM}$ siRNA-calcium phosphate precipitates for $12-16 \mathrm{~h}$ before removal and maintained for $72 \mathrm{~h}$ until experiments.

\section{RNA isolation \& PCR}

RNA was isolated using Trizol (Invitrogen) and cDNA was generated by reverse transcription using the SuperScript $^{\circledR}$ VILO $^{\mathrm{TM}}$ CDNA kit (Invitrogen) according to the manufacturer's instructions. Fifteen ng RNA per reaction were used to run the qPCR using pre-designed Taqman probes from Invitrogen/Applied Biosystems.

\section{2-Deoxy- $\left[{ }^{3} \mathrm{H}\right]$ glucose uptake and cell surface GLUT4myc}

L6GLUT4myc myoblasts grown in 24-well plates were serum-deprived for $2 \mathrm{~h}$ and then treated with or without insulin (100 $\mathrm{nM}, 20 \mathrm{~min})$. 2-Deoxy- $\left[{ }^{3} \mathrm{H}\right]$ glucose uptake and cell surface density of GLUT4myc [59] were measured as described previously.

\section{Immunoblotting}

After treatments, cells were scraped into lysis buffer (20 mM Tris- $\mathrm{HCl}, 138 \mathrm{mMNaCl}, 2.7 \mathrm{mM} \mathrm{KCl}, 1 \mathrm{mM}$ $\mathrm{MgCl}, 2,5 \%$ glycerol and1\% Nonidet-P40) supplemented with protease and phosphatase inhibitors $(5 \mathrm{mM}$ EDTA, $1 \mathrm{mM} \mathrm{Na} \mathrm{VO}_{4}, 20 \mathrm{mM} \mathrm{NaF}, 1 \mathrm{mM}$ dithiothreitol, protein inhibitor cocktail; Sigma-Aldrich) and protein content measured by the Bradford assay. For western blotting, proteins were boiled in Laemmli buffer, separated by SDS-PAGE and transferred onto PVDF membrane (Bio-Rad, Hercules, CA). Membranes were then blotted using primary antibodies $\left(4^{\circ} \mathrm{C}\right.$ overnight), washed and peroxidase-coupled secondary antibody $(1: 10,000)$ was applied for $1 \mathrm{~h}$ at room temperature. Membranes were developed using enhanced chemiluminescence (ECL, Perkin Elmer), and films analyzed using NIH ImageJ software. 
Intracellular reactive oxygen species (ROS) production Cytoplasmic ROS level in L6GLUT4myc were assayed using the 5-(and-6)-chloromethyl-2',7'-dichlorodihydrofluorescein diacetate acetyl ester (CM-H2DCFDA, Invitrogen). Cells grown in 12-well plates were treated with $0.2 \mathrm{mM}$ palmitate, palmitoleate or BSA control for $24 \mathrm{~h}$, then incubated with $10 \mu \mathrm{M}$ CM-H2DCFDA at $37^{\circ} \mathrm{C}$ for $30 \mathrm{~min}$ in PBS. $\mathrm{H}_{2} \mathrm{O}_{2}(100 \mu \mathrm{M})$ was used as positive control and it rendered a consistent 3-fold increase in ROS. Cells were washed and solubilized in Triton-X100 1\% $(\mathrm{v} / \mathrm{v}$ in distillated water) and fluorescence measured in a plate reader at $495 \mathrm{~nm}$ excitation and $520 \mathrm{~nm}$ emission. Results were normalized to the protein content of cell lysates.

\section{Generation of muscle conditioned medium}

L6GLUT4myc cells grown to pre-confluence were treated with $0.2 \mathrm{mM}$ palmitate, palmitoleate or BSA control in $\alpha$ MEM supplemented with $10 \%$ FBS, for 24 h. The fatty acids and BSA solutions were then removed, cell monolayers thoroughly rinsed with $\mathrm{PBS}$ and incubated with fresh $\alpha$ MEM supplemented with 2\% FBS for another $24 \mathrm{~h}$. The supernatants collected after this step represent the conditioned media $(\mathrm{CM})$ and depending on whether muscle cells were pretreated with BSA, palmitate or palmitoleate, the CM are termed CM-BSA, CMPA or CM-PO. CM were centrifuged at 10,000 RPM for $5 \mathrm{~min}$ to pellet debris, aliquoted and immediately frozen at $-80^{\circ} \mathrm{C}$. At the end of these incubations, cell viability in the corresponding cell monolayers was $>85 \%$ (MTT test). Quantification of non-esterified fatty acids in CM was performed using the NonEsterified Fatty Acid-HR kit (Wako) as per the manufacturer's instructions.

\section{Characterization and inactivation of muscle conditioned medium}

Cytokines in the $\mathrm{CM}$ were determined using the rat cytokine profiler array 2 (Ray Biotech) as per the manufacturer's instructions. Signal detection was done using $\mathrm{x}$-ray films and care was taken to expose the CM-BSA and CM-PA arrays equally.

$\mathrm{CM}$ were either heated at $95^{\circ} \mathrm{C}$ for 15 or treated with $100 \mu \mathrm{g} / \mathrm{mL}$ proteinase K (Sigma Aldrich) for $2 \mathrm{~h}$, then heat inactivated as above to avoid damage of macrophages by proteinase $\mathrm{K}$.

\section{Immunofluorescence staining and cell shape score}

All reagents were diluted in PBS supplemented with calcium and magnesium, and cells were washed with PBS between each staining step. Cells cultured on glass coverslips were fixed with $3 \%$ paraformaldehyde for 30 min and incubated sequentially with $0.1 \%$ Triton-X100 for $10 \mathrm{~min}$, $5 \% \mathrm{BSA}$ for $30 \mathrm{~min}$, and rhodamine- phalloidin for $45 \mathrm{~min}$. Nuclei were counterstained with 1 $\mu \mathrm{g} / \mathrm{ml}$ DAPI (Sigma Aldrich) for $5 \mathrm{~min}$. Coverslips were then mounted onto glass slides and stored at $4^{\circ} \mathrm{C}$ until analysis. Fluorescence images were captured on a spinning disk confocal microscope using a 40X air objective. For an analysis unbiased by cell shape, fields were selected by viewing nuclear staining (DAPI). Subsequent, rhodamine fluorescence was captured in $\mathrm{x}, \mathrm{y}$ and $\mathrm{z}$ axes to detect actin within the whole cell volume. At least 300 cells were used for analysis per condition ( $>30$ fields).

\section{Shape quantification}

For each field, extended focus images (fusion of all $\mathrm{z}$ stack images) were created and image analysis was performed using ImageJ software (http://rsb.info.nih.gov/ij). For each field, the image was transformed in 8 bits and a median filter (2 pixel radius) was applied to approximate the distribution of staining intensity. Binary image masks were then created using an automatic threshold to create an image including all fluorescence data above background. Detection of surface area was done using of the "Analyze Particles" option with a threshold of 100 pixels in order to exclude all small dots of fluorescence outside of cells. Quantitative fluorescence data (area, circularity) were exported from ImageJ for further analysis and presentation. Area results given in pixel were then transformed in $\mu \mathrm{m}^{2}$ according to the scale. Additionally, the elongated $v s$. round phenotype was determined by manual counting of the cells and eye determination of the shape. This quantification was done by a sample identityblinded experimenter to avoid subjective bias.

\section{Adhesion assay}

RAW macrophages were pre-stained with calcein-AM $(1 \mu \mathrm{g} / \mathrm{ml})$ for $20 \mathrm{~min}$ and then centrifuged, washed and re-suspended in each test $\mathrm{CM}$ from the muscle cell cultures. After $30 \mathrm{~min}$, macrophages were seeded onto a 24-well plate and allowed to adhere for $15 \mathrm{~min}$. Medium was then removed, cells were washed and the remaining adherent cells were lysed in 1\% Triton-X100. Fluorescence at excitation/emission of $495 / 515 \mathrm{~nm}$ was proportional to the number of adhered cells.

\section{Statistical analysis}

Statistical analysis was performed using GraphPad Prism software (GraphPad Software, San Diego, CA). Twogroups comparison was performed using Student's paired t-test with Welsh correction for inequality of variances as necessary. Results of time courses were analyzed by two-way analysis of variance followed as appropriate by Bonferroni post-tests. One-way ANOVA was used to test differences between groups. Data are presented as means \pm SD (if $n=3$ ) or SEM (if $n \geq 4$ ), and statistical significance was set at $\mathrm{P}<0.05$. 


\section{Additional file}

Additional file 1: Figure S1. Cytokine composition of the CM. CM-BSA and CM-PA were tested for their cytokine and chemokine content using commercially available rat profiler arrays from Ray Biotech. C) Map of the cytokines detected by the membrane. Figure S2. Palmitate-induced cytokine expression occurs through NFKB pathway. A) NFkB was silenced using specific siRNA to the p65 subunit (p65) or control non-related siRNA (NR) before treatment of cells for 24h with 0.2 mM palmitate or BSA. B) TLR2 and TLR4 were inhibited using a cellpermeant MYD88 inhibitory peptide (MYD-Inh) and results compared to a control scramble peptide. IL-6 expression was then measured by qPCR as previously. Inset: IL-6 expression measured in response to BSA and 10 $\mathrm{ng} / \mathrm{mL}$ LPS for $24 \mathrm{~h}$ in presence or not of the MYD88 inhibitory peptide, expressed relative to the BSA control. All results were reported as fold change, relative to $B S A \pm S D$ from at least 3 independent experiments $(n \geq 3)$. ${ }^{*} P<0.05,{ }^{* *} P<0.01$, ns $=$ not significant. Figure S3. Inactivation of the CM prevents TNFa expression in macrophages. A) CM from L6GLUT4myc cells was generated as described in methods and inactivated using boiling $\left(95^{\circ} \mathrm{C}, 15 \mathrm{~min}\right)$ or treatment with proteinase $\mathrm{K}$ $\left(100 \mu \mathrm{g} / \mathrm{mL}\right.$ for 2 hours at $40^{\circ} \mathrm{C}$ followed by heat inactivation of the enzyme at $95^{\circ} \mathrm{C}$ for $15 \mathrm{~min}$ ). CM was then tested for its ability to induce TNFa expression in RAW264.7 macrophages. Gene expression was measured by qPCR as described in Methods. Results were reported as a ratio over the CM-BSA control, mean \pm SEM from 5 independent experiments $(n=5)$. B) Results from the same experiments were expressed as a ratio PA over BSA. ${ }^{*} \mathrm{P}<0.05$ versus BSA control. Figure S4. Inhibition of ERK prevents macrophage adhesion. RAW cells were pretreated with 20 MM PD98059 for 30 minutes. Measurement of RAW cells adhesion in response to the CM was then performed as described in methods. Results were reported as \% of the CM-BSA control, mean \pm SD from 4 independent experiments $(n=4)$. ${ }^{*} P<0.05, n s=$ not significant.

\section{Abbreviations}

BSA: Bovine serum albumin; CM: Conditioned media; CM-BSA: Conditioned media from BSA-pretreated myoblasts; CM-PA: Conditioned media from palmitate-pretreated myoblasts; CM-PO: Conditioned media from palmitoleate-pretreated myoblasts; HFD: High fat diet; IKBa: Inhibitor of nuclear factor kappa-B; IL: Interleukin; INF: Interferon; NF-kB: Nuclear factor kappa-B; PA: Palmitate; PO: Palmitoleate; ROS: Reactive oxygen species; TNF: Tumor necrosis factor

\section{Competing interests}

The authors declare that they have no competing interests.

\section{Authors' contributions}

NJP participated in the design of the study, coordinated and carried out the majority of the experiments, performed the statistical analysis and participated in writing of the manuscript. KA carried out experiments and analysis concerning macrophage signalling, spreading and adhesion. PJB participated in the design of the study, helped with the experiments and writing of the manuscript. TTC carried out experiments involving gene silencing and surface GLUT4 detection. AK conceived the study and participated in its design, coordination, and writing of the manuscript. All authors read and approved the final manuscript.

\section{Acknowledgements}

This project was supported by grant MT12601 from the Canadian Institutes of Health Research (CIHR) to A. Klip. NJP was supported by postdoctoral awards from the Research Training Centre at The Hospital for Sick Children and the Banting and Best Diabetes Centre of the University of Toronto. KA was supported by a summer studentship from the Banting and Best Diabetes Centre of the University of Toronto. TTC was supported by a CIHR Banting Doctoral Award.

Received: 6 September 2012 Accepted: 16 October 2012

Published: 19 October 2012

\section{References}

1. World Health Organization (WHO): Obesity and overweight (Fact sheet No311): WHO; 2011. http://www.who.int/mediacentre/factsheets/fs311/en/

2. Sanada $H$, Yokokawa $H$, Yoneda M, Yatabe J, Sasaki Yatabe M, M Williams S, A Felder R, A Jose P: High Body Mass Index is an Important Risk Factor for the Development of Type 2 Diabetes. Intern Med 2012, 51:1821-1826.

3. Sung K-C, Jeong W-S, Wild SH, Byrne CD: Combined influence of insulin resistance, overweight/obesity, and fatty liver as risk factors for type 2 diabetes. Diabetes Care 2012, 35:717-722.

4. Sabin MA, De Hora M, Holly JMP, Hunt LP, Ford AL, Williams SR, Baker JS, Retallick CJ, Crowne EC, Shield JPH: Fasting nonesterified fatty acid profiles in childhood and their relationship with adiposity, insulin sensitivity, and lipid levels. Pediatrics 2007, 120:e1426-e1433.

5. Zák A, Vecka M, Tvrzická E, Hrubý M, Novák F, Papezová H, Lubanda H, Veselá L, Stanková B: Composition of plasma fatty acids and noncholesterol sterols in anorexia nervosa. Physiol Res 2005, 54:443-451.

6. Coll T, Palomer X, Blanco-Vaca F, Escolà-Gil JC, Sánchez RM, Laguna JC, Vázquez-Carrera M: Cyclooxygenase 2 inhibition exacerbates palmitate-induced inflammation and insulin resistance in skeletal muscle cells. Endocrinology 2010, 151:537-548.

7. Lee JS, Pinnamaneni SK, Eo SJ, Cho IH, Pyo JH, Kim CK, Sinclair AJ, Febbraio MA, Watt MJ: Saturated, but Not N-6 polyunsaturated, fatty acids induce insulin resistance: role of intramuscular accumulation of lipid metabolites. J App/ Physiol 2006, 100:1467-1474.

8. Yu C, Chen Y, Cline GW, Zhang D, Zong H, Wang Y, Bergeron R, Kim JK, Cushman SW, Cooney GJ, Atcheson B, White MF, Kraegen EW, Shulman Gl: Mechanism by which fatty acids inhibit insulin activation of insulin receptor substrate-1 (IRS-1)-associated phosphatidylinositol 3-kinase activity in muscle. J Biol Chem 2002, 277:50230-50236.

9. Dimopoulos N, Watson M, Sakamoto K, Hundal HS: Differential effects of palmitate and palmitoleate on insulin action and glucose utilization in rat L6 skeletal muscle cells. Biochem J 2006, 399:473-481.

10. Mozaffarian D, Cao H, King IB, Lemaitre RN, Song X, Siscovick DS, Hotamisligil GS: Circulating palmitoleic acid and risk of metabolic abnormalities and new-onset diabetes. Am J Clin Nutr 2010, 92:1350-1358.

11. Gregor MF, Hotamisligil GS: Inflammatory mechanisms in obesity. Annu Rev Immunol 2011, 29:415-445.

12. Nguyen MTA, Favelyukis $S$, Nguyen $A-K$, Reichart $D$, Scott PA, Jenn $A$, Liu-Bryan R, Glass CK, Neels JG, Olefsky JM: A subpopulation of macrophages infiltrates hypertrophic adipose tissue and is activated by free fatty acids via Toll-like receptors 2 and 4 and JNK-dependent pathways. J Biol Chem 2007, 282:35279-35292.

13. Weisberg SP, McCann D, Desai M, Rosenbaum M, Leibel RL, Ferrante AW Jr: Obesity is associated with macrophage accumulation in adipose tissue. J Clin Invest 2003, 112:1796-1808.

14. Kewalramani G, Fink LN, Asadi F, Klip A: Palmitate-activated macrophages confer insulin resistance to muscle cells by a mechanism involving protein kinase C $\theta$ and $\varepsilon$. PLoS One 2011, 6:e26947.

15. Lumeng CN, Deyoung SM, Saltiel AR: Macrophages block insulin action in adipocytes by altering expression of signaling and glucose transport proteins. Am J Physiol Endocrinol Metab 2007, 292:E166-E174.

16. Lumeng CN, Bodzin JL, Saltiel AR: Obesity induces a phenotypic switch in adipose tissue macrophage polarization. J Clin Invest 2007, 117:175-184.

17. Zeyda M, Farmer D, Todoric J, Aszmann O, Speiser M, Györi G, Zlabinger GJ, Stulnig TM: Human adipose tissue macrophages are of an antiinflammatory phenotype but capable of excessive pro-inflammatory mediator production. Int J Obes (Lond) 2007, 31:1420-1428.

18. Samokhvalov V, Bilan PJ, Schertzer JD, Antonescu CN, Klip A: Palmitate- and lipopolysaccharide-activated macrophages evoke contrasting insulin responses in muscle cells. Am J Physiol Endocrinol Metab 2009, 296:E37-E46.

19. Suganami T, Tanimoto-Koyama K, Nishida J, Itoh M, Yuan X, Mizuarai S, Kotani H, Yamaoka S, Miyake K, Aoe S, Kamei Y, Ogawa Y: Role of the Tolllike receptor 4/NF-kappaB pathway in saturated fatty acid-induced inflammatory changes in the interaction between adipocytes and macrophages. Arterioscler Thromb Vasc Biol 2007, 27:84-91.

20. Hotamisligil GS, Murray DL, Choy LN, Spiegelman BM: Tumor necrosis factor alpha inhibits signaling from the insulin receptor. Proc Natl Acad Sci USA 1994, 91:4854-4858.

21. Lee YS, Li P, Huh JY, Hwang IJ, Lu M, Kim JI, Ham M, Talukdar S, Chen A, Lu WJ, Bandyopadhyay GK, Schwendener R, Olefsky J, Kim JB: Inflammation is 
necessary for long-term but not short-term high-fat diet-induced insulin resistance. Diabetes 2011, 60:2474-2483.

22. DeFronzo RA, Tripathy D: Skeletal muscle insulin resistance is the primary defect in type 2 diabetes. Diabetes Care 2009, 32(Suppl 2):S157-163.

23. Brigitte M, Schilte C, Plonquet A, Baba-Amer Y, Henri A, Charlier C, Tajbakhsh S, Albert M, Gherardi RK, Chrétien F: Muscle resident macrophages control the immune cell reaction in a mouse model of notexin-induced myoinjury. Arthritis Rheum 2010, 62:268-279.

24. Chazaud B, Brigitte M, Yacoub-Youssef H, Arnold L, Gherardi R, Sonnet C, Lafuste $P$, Chretien F: Dual and beneficial roles of macrophages during skeletal muscle regeneration. Exerc Sport Sci Rev 2009, 37:18-22.

25. Fink LN, Oberbach A, Jensen TE, Sams A, Blüher M, Klip A: MuscleInfiltrating Macrophages in Type 2 Diabetes. Diabetes 2012, 61:106. OR.

26. Patsouris D, Li P-P, Thapar D, Chapman J, Olefsky JM, Neels JG: Ablation of CD11c-positive cells normalizes insulin sensitivity in obese insulin resistant animals. Cell Metab 2008, 8:301-309.

27. Varma V, Yao-Borengasser A, Rasouli N, Nolen GT, Phanavanh B, Starks T, Gurley C, Simpson P, McGehee RE Jr, Kern PA, Peterson CA: Muscle inflammatory response and insulin resistance: synergistic interaction between macrophages and fatty acids leads to impaired insulin action. Am J Physiol Endocrinol Metab 2009, 296:E1300-E1310.

28. Niu W, Huang C, Nawaz Z, Levy M, Somwar R, Li D, Bilan PJ, Klip A Maturation of the regulation of GLUT4 activity by p38 MAPK during L6 cell myogenesis. J Biol Chem 2003, 278:17953-17962.

29. Stefan N, Kantartzis K, Celebi N, Staiger H, Machann J, Schick F, Cegan A, Elcnerova M, Schleicher E, Fritsche A, Häring H-U: Circulating palmitoleate strongly and independently predicts insulin sensitivity in humans. Diabetes Care 2010, 33:405-407.

30. Püttmann M, Krug H, von Ochsenstein E, Kattermann R: Fast HPLC determination of serum free fatty acids in the picomole range. Clin Chem 1993, 39:825-832.

31. Tanti J-F, Jager J: Cellular mechanisms of insulin resistance: role of stressregulated serine kinases and insulin receptor substrates (IRS) serine phosphorylation. Curr Opin Pharmacol 2009, 9:753-762.

32. Kefaloyianni E, Gaitanaki C, Beis I: ERK1/2 and p38-MAPK signalling pathways, through MSK1, are involved in NF-KB transactivation during oxidative stress in skeletal myoblasts. Cell Signal 2006, 18:2238-2251.

33. JeBailey L, Wanono O, Niu W, Roessler J, Rudich A, Klip A: Ceramide- and oxidant-induced insulin resistance involve loss of insulin-dependent Rac-activation and actin remodeling in muscle cells. Diabetes 2007, 56:394-403.

34. Pillon NJ, Croze ML, Vella RE, Soulère L, Lagarde M, Soulage CO: The Lipid Peroxidation By-Product 4-Hydroxy-2-Nonenal (4-HNE) Induces Insulin Resistance in Skeletal Muscle Through Both Carbonyl and Oxidative Stress. Endocrinology 2012, 153:2099-2111

35. Zhang J, Gao Z, Yin J, Quon MJ, Ye J: S6K directly phosphorylates IRS-1 on Ser-270 to promote insulin resistance in response to TNF-(alpha) signaling through IKK2. J Biol Chem 2008, 283:35375-35382.

36. Lambernd S, Taube A, Schober A, Platzbecker B, Görgens SW, Schlich R, Jeruschke K, Weiss J, Eckardt K, Eckel J: Contractile activity of human skeletal muscle cells prevents insulin resistance by inhibiting proinflammatory signalling pathways. Diabetologia 2012, 55:1128-1139.

37. Kim TH, Choi SE, Ha ES, Jung JG, Han SJ, Kim HJ, Kim DJ, Kang Y, Lee KW: IL-6 induction of TLR-4 gene expression via STAT3 has an effect on insulin resistance in human skeletal muscle. Acta Diabetol 2011.

38. Ivashkiv LB: Inflammatory signaling in macrophages: transitions from acute to tolerant and alternative activation states. Eur J Immunol 2011, 41:2477-2481.

39. Williams LM, Ridley AJ: Lipopolysaccharide induces actin reorganization and tyrosine phosphorylation of Pyk2 and paxillin in monocytes and macrophages. J Immunol 2000, 164:2028-2036.

40. Mantovani A, Garlanda C, Locati M: Macrophage diversity and polarization in atherosclerosis: a question of balance. Arterioscler Thromb Vasc Biol 2009, 29:1419-1423.

41. Green CJ, Macrae K, Fogarty S, Hardie DG, Sakamoto K, Hundal HS: Counter-modulation of fatty acid-induced pro-inflammatory nuclear factor $\mathrm{KB}$ signalling in rat skeletal muscle cells by AMP-activated protein kinase. Biochem J 2011, 435:463-474.

42. Weigert C, Brodbeck K, Staiger H, Kausch C, Machicao F, Häring HU, Schleicher ED: Palmitate, but not unsaturated fatty acids, induces the expression of interleukin- 6 in human myotubes through proteasome- dependent activation of nuclear factor-kappaB. J Biol Chem 2004, 279:23942-23952

43. Senn JJ: Toll-like receptor-2 is essential for the development of palmitate-induced insulin resistance in myotubes. J Biol Chem 2006, 281:26865-26875.

44. Shi $H$, Kokoeva MV, Inouye $K$, Tzameli I, Yin H, Flier JS: TLR4 links innate immunity and fatty acid-induced insulin resistance. J Clin Invest 2006, 116:3015-3025.

45. Huang S, Rutkowsky JM, Snodgrass RG, Ono-Moore KD, Schneider DA, Newman JW, Adams SH, Hwang DH: Saturated fatty acids activate TLR-mediated proinflammatory signaling pathways. J Lipid Res 2012 53:2002-2013

46. Davis JE, Gabler NK, Walker-Daniels J, Spurlock ME: Tlr-4 deficiency selectively protects against obesity induced by diets high in saturated fat. Obesity 2008, 16:1248-1255.

47. Radin MS, Sinha S, Bhatt BA, Dedousis N, O'Doherty RM: Inhibition or deletion of the lipopolysaccharide receptor Toll-like receptor- 4 confers partial protection against lipid-induced insulin resistance in rodent skeletal muscle. Diabetologia 2008, 51:336-346.

48. Tamrakar AK, Schertzer JD, Chiu T, Foley KP, Bilan PJ, Philpott DJ, Klip A NOD2 activation induces muscle cell-autonomous innate immune responses and insulin resistance. Endocrinology 2010, 151:5624-5637.

49. Yuzefovych L, Wilson G, Rachek L: Different effects of oleate vs. palmitate on mitochondrial function, apoptosis, and insulin signaling in L6 skeletal muscle cells: role of oxidative stress. Am J Physiol Endocrinol Metab 2010, 299:E1096-E1105.

50. Green CJ, Pedersen M, Pedersen BK, Scheele C: Elevated NF-kB activation is conserved in human myocytes cultured from obese type 2 diabetic patients and attenuated by AMP-activated protein kinase. Diabetes 2011, 60:2810-2819

51. Calura E, Cagnin S, Raffaello A, Laveder P, Lanfranchi G, Romualdi C: Meta-analysis of expression signatures of muscle atrophy: gene interaction networks in early and late stages. BMC Genomics 2008, 9:630.

52. Tantiwong P, Shanmugasundaram K, Monroy A, Ghosh S, Li M, DeFronzo RA, Cersosimo E, Sriwijitkamol A, Mohan S, Musi N: NF-kB activity in muscle from obese and type 2 diabetic subjects under basal and exercise-stimulated conditions. Am J Physiol Endocrinol Metab 2010, 299:E794-E801.

53. Jové M, Planavila A, Laguna JC, Vázquez-Carrera M: Palmitate-induced interleukin 6 production is mediated by protein kinase $C$ and nuclearfactor kappaB activation and leads to glucose transporter 4 downregulation in skeletal muscle cells. Endocrinology 2005, 146:3087-3095.

54. Henstridge DC, Bruce CR, Pang CP, Lancaster Gl, Allen TL, Estevez E, Gardner T, Weir JM, Meikle PJ, Lam KSL, Xu A, Fujii N, Goodyear LJ, Febbraio MA: Skeletal muscle-specific overproduction of constitutively activated c-Jun N-terminal kinase (JNK) induces insulin resistance in mice. Diabetologia 2012, 55(10):2769-2778.

55. Kapur S, Marcotte B, Marette A: Mechanism of adipose tissue iNOS induction in endotoxemia. Am J Physiol 1999, 276:E635-E641.

56. Mendoza MC, Er EE, Zhang W, Ballif BA, Elliott HL, Danuser G, Blenis J: ERK-MAPK drives lamellipodia protrusion by activating the WAVE2 regulatory complex. Mol Cell 2011, 41:661-671.

57. Aflaki E, Balenga NAB, Luschnig-Schratl P, Wolinski H, Povoden S, Chandak PG, Bogner-Strauss JG, Eder S, Konya V, Kohlwein S-D, Heinemann A, Kratky D: Impaired Rho GTPase activation abrogates cell polarization and migration in macrophages with defective lipolysis. Cell Mol Life Sci 2011, 68:3933-3947.

58. Ruffell D, Mourkioti F, Gambardella A, Kirstetter P, Lopez RG, Rosenthal N, Nerlov C: A CREB-C/EBPbeta cascade induces M2 macrophage-specific gene expression and promotes muscle injury repair. Proc Natl Acad SCi USA 2009, 106:17475-17480.

59. Wang Q, Khayat Z, Kishi K, Ebina Y, Klip A: GLUT4 translocation by insulin in intact muscle cells: detection by a fast and quantitative assay. FEBS Lett 1998, 427:193-197.

\section{doi:10.1186/1478-811X-10-30}

Cite this article as: Pillon et al:: Muscle cells challenged with saturated fatty acids mount an autonomous inflammatory response that activates macrophages. Cell Communication and Signaling 2012 10:30. 